\title{
EXPERIMENTAL STREPTOCOCCIC TONSILLITIS \\ THE APPARENT INEFFICACY OF STREPTOCOCCIC VACCINE AS PROPHYLACTIC
}

\author{
DEWAYNE G. RICHEY
}

From the U. S. Naval Medical School, Washington, D. C.

It has long been recognized that acute tonsillitis is of bacterial origin and infectious nature. Even as early as 1895, Fraenkel and Macintyre $^{1}$ called attention to this fact and, in the same year, Sendziak ${ }^{2}$ noted the frequency of streptococci, staphylococci and corynebacteria in tonsillar cultures, taken in situ. Davis, ${ }^{3}$ in a series of cultures from the extirpated tonsils of 113 cases, found virulent hemolytic streptococci to be, as a rule, the predominant organism and observed that pneumococci were encountered more frequently on the surface of the tonsil, whereas streptococci occurred more commonly in the lacunae. The same author, in another work, ${ }^{4}$ described the actinomyces-like granules in the crypts of the tonsils and mentioned the occurrence of nonpathogenic, anaerobic, fusiform bacilli, streptococci and spirilla in them. More recently, Pilot and Davis ${ }^{5}$ isolated both hemolytic streptococcus and $S$. viridans from these granules. The green strains showed marked anaerobic tendencies, while the hemolytic did not. According to the classification of Holman, ${ }^{8}$ the hemolytic streptococci corresponded to $\mathrm{S}$. pyogenes and $\mathrm{S}$. anginosus and the viridans to $S$. mitis and $S$. salivarius. Holman encountered these four varieties most frequently in the nose and throat. The weight of evidence, both clinical and cultural, points to the causative organisms of acute tonsillitis as being streptococci or, in the minority of cases, staphylococci and the mode of dissemination to be either direct or nearly direct contact. Other factors, of course, such as age, climatic conditions and resistancelowering processes may play a predisposing rôle.

Received for publication May 22, 1919.

1 Brit. Med. Jour., 1895, 2, p. 1018.

2 Jour. Laryngol. (London), 1895, 9, p. 263.

8 Jour. Infect. Dis., 1912, 10, p. 148.

- Ibid., 1914, 14, p. 144.

s Ibid., 1918, 23, p. 565.

- Jour. Med. Research, 1916, 34, p. 377. 
Inoculations of living organisms into the nasopharynx have been made on the human subject by several observers. Usually viable cultures of Staphylococcus aureus were sprayed into the nares and throats of B. diphtheriae carriers. Page ${ }^{\tau}$ treated seven cases in this way with no untoward results. Catlin, Scott and Day ${ }^{8}$ encountered no cases of tonsillitis in eight instances. Lorenz and Ravene $1^{9}$ reported one very mild case of laryngitis following the instillation of staphylococci in a series of seventeen cases, while Alden, ${ }^{10}$ in sixteen cases, noted "sore throat" in two and pharyngitis in one. Similarly, Davis ${ }^{11}$ recounts the development of tonsillitis 26 hours after the introduction of staphylococci into the nasopharynx of a carrier of $\mathrm{B}$. diphtheriae. This extremely low percentage of tonsillitis cases following such procedure is very interesting and may be attributed, in part, to the attenuation of the cultures employed.

I have not found any account of experimental throat infections in man due to the use of secretions from the upper respiratory passages of the sick.

The present report deals with the occurrence of sixteen cases of tonsillitis, due to infection with secretions from the sick, which developed during the course of some experiments on human volunteers, conducted by medical officers of the U. S. Navy and U. S. Public Health Service, in an attempt to ascertain, if possible, the mode of dissemination and cause of influenza.

These experiments were three in number. The first two took place simultaneously at San Francisco and Boston during November and December, 1918, the third at Boston during February and March, 1919.

A detailed account of these researches will be published in a forthcoming bulletin of the Hygienic Laboratory, U. S. Public Health Service. It is not the purpose of this communication to discuss the results of these investigations from the standpoint of influenza, but to emphasize the production of tonsillitis in 16 of the volunteers. For this reason, only the methods and data pertinent to the subject at hand will be indicated.

All of the 155 volunteers were from the enlisted personnel of the U. S. Navy. Their ages ranged from 15 to 36 years, the average being, approximately, 20 years. Save for the occasional incidence of hypertrophic tonsils, the men were

1 Arch. Int. Med., 1911, 7, p. 16.

S Jour. Am. Med. Assn., 1911, 57, p. 1452.

- Jour. Am. Med. Assn., 1912, 59, p. 692.

10 Jour. Am. Med. Assn., 1913, 60, p. 1876.

11 Jour. Am. Med. Assn., 1913, 61, p. 393. 
in excellent condition. The histories revealed the fact that they had enjoyed good health, some never having been ill. Less than $10 \%$ of them had experienced repeated attacks of tonsillitis and none had suffered from "sore throat" for several weeks before the experiments began.

The essential differences between the three groups were that the one at San Francisco had been under absolute quarantine since Sept. 23, 1918, while the Boston contingents had experienced a contact with influenza patients which varied from practically no exposure to the disease during the recent pandemic to the most intimate association with it. There were no cases of influenza on the San Francisco station until Dec. 6, 1918, sixteen days after the quarantine had been removed. For purposes of experimentation, therefore, the San Francisco group would have been ideal were it not for the fact that, on Oct. 12, 15, and 18,1918 -approximately a month before the experiments were inauguratedthe entire personnel had been given a vaccine of which one mil contained:

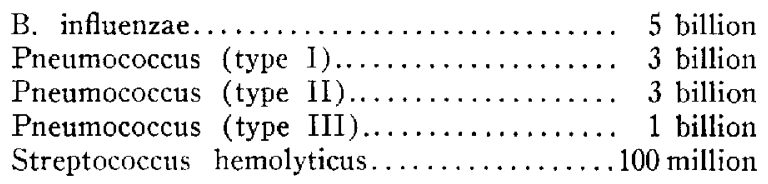

The doses were $0.5,0.8$ and 1.0 mil, respectively. The inoculation produced a certain degree of local reaction along with headache, generalized pains and a slight increase in temperature. These were most marked after the second infection, but never persisted longer than 48 hours. An account of this procedure has been reported by Minaker and Irvine."

Summary of Data Obtained in the Study of Experimental Streptococcic Tonsillitis

\begin{tabular}{|c|c|c|c|c|c|c|c|}
\hline Place & Time & $\begin{array}{l}\text { Total } \\
\text { Number } \\
\text { of Vol- } \\
\text { unteers }\end{array}$ & $\begin{array}{c}\text { Total } \\
\text { Number } \\
\text { of Inoeu- } \\
\text { lations }\end{array}$ & $\begin{array}{c}\text { Total } \\
\text { Number } \\
\text { Inocula- } \\
\text { tions of } \\
\text { Crude } \\
\text { Secretions } \\
\text { into } \\
\text { Naso- } \\
\text { pharynx }\end{array}$ & $\begin{array}{c}\text { Total } \\
\text { Number } \\
\text { Volunteers } \\
\text { Receiving } \\
\text { Orude } \\
\text { Secretions } \\
\text { into } \\
\text { Naso- } \\
\text { pharynx }\end{array}$ & $\begin{array}{c}\text { Total } \\
\text { Number } \\
\text { Cases of } \\
\text { Tonsillitis }\end{array}$ & $\begin{array}{c}\text { Percentage } \\
\text { of Vol- } \\
\text { unteers } \\
\text { Inoculated } \\
\text { with Crude } \\
\text { Secretions } \\
\text { Who } \\
\text { Developed } \\
\text { 'Tonsillitis }\end{array}$ \\
\hline & $\begin{array}{c}\text { Nov,-Dee., } \\
1918\end{array}$ & 50 & 40 & 14 & 14 & 3 & 21.4 \\
\hline Boston & $\begin{array}{c}\text { Nov-Dec., } \\
1918\end{array}$ & 62 & 104 & 49 & 32 & 1 & 2.0 \\
\hline Boston & $\begin{array}{c}\text { Feb.-Mar., } \\
1919\end{array}$ & 43 & 82 & 61 & 40 & 12 & 19.6 \\
\hline Total..... & n.w. & 155 & 226 & 124 & 86 & 16 & 12.9 \\
\hline
\end{tabular}

From the table it can be seen that 155 men were utilized in the three experiments. On these men 226 inoculations were made, of which 124 consisted in the transference of crude nasopharyngeal washings and bronchial secretions from certain individuals presumably ill of influenza into the noses and throats of 86 different men. Sixteen of these men developed tonsillitis. Only two of them showed hypertrophic tonsils before inoculation. No volunteer receiving filtered secretions showed a subsequent throat condition.

12 Jour. Am. Med. Assn., 1919, 72, p. 847. 
In the first Boston experiments tonsillitis occurred in only one of the forty-nine $(2 \%)$ volunteers receiving crude secretions. In the second series of experiments at Boston, 12 of sixty-one (19.6\%) became ill of this disease. Six of these 12 cases occurred in one squad where, in an endeavor to obtain an extremely early case of influenza, nasopharyngeal washings and bronchial secretions were procured from an individual who was suspected to be developing influenza, but who later proved to have tonsillitis. If these were disregarded, it would leave 6 cases in 61 inoculations, or $9.8 \%$ for this group. In the San Francisco experiments, tonsillitis occurred in 3 of 14 men $(21.4 \%)$ into whose noses were instilled unfiltered nasopharyngeal washings and bronchial secretions.

The cases of tonsillitis referred to in this report were clinically typical. All exhibited more or less purulent exudate in the crypts of one or both tonsils at some stage of their illness. They all made an uneventful recovery, except one man who developed a right-sided otitis media which proceeded to recovery.

The incubation period was, in all but two instances, between 36 and 72 hours. The two exceptions were encountered in the second Boston investigations, and the periods of incubation were 5 and 6 days, respectively. The cases in a given group became ill within a few hours of each other, so that, even though the other members of the group were undergoing experimentation they were in contact with those developing the disease, the time element clearly indicated a common source of infection.

In every case a hemolytic streptococcus was found to be the predominating organism in the cultures taken from the tonsils in the early stages of illness, and it was noted that on the fresh, human blood-agar plate the colonies were very similar to those seen in the cultures from the donors of the respective groups. All corresponded to the "beta" type of Smith and Brown, ${ }^{13}$ and Smillie. ${ }^{14}$ No difficulty was occasioned in cultivating them, aerobically, on human blood agar $(5 \%)$ and serum broth. Those cultures from donors and recipients which were transplanted to carbohydrate mediums fermented lactose and salicin with the formation of acid, corresponding to $\mathrm{S}$. pyogenes in Holman's classification.

13 Jour. Med. Research, 1914-15, 31, p. 455.

14 Jour. Infect. Dis., 1917, 20, p. 45. 
By reverting to the table, it will be noted that the highest percentage of cases of tonsillitis occurred in the San Francisco experiments. As mentioned before, the volunteers in this group had received, one month previously, a vaccine, $1 \mathrm{mil}$ of which contained, along with other organisms, 100 million hemolytic streptococci which had been isolated from the upper respiratory passages of two influenzal patients. In neither of the Boston series of experiments were any volunteers used who had been given vaccine. It is not intended that one deduce from this that the vaccine sensitized the recipients to subsequent streptococcic infection.

Naturally, in this regard, several phases of the problems of vaccinotherapy present themselves. The early endeavors of Pasteur and Koch have been amplified and given to the profession in a more concrete form by Wright. ${ }^{15}$ In the last decade of the 19th century von Behring and Knorr $^{16}$ found that rabbits immunized by a given strain of streptococci were protected against that strain. Since this time many investigations have been pursued to ascertain the efficacy of active and passive immunization against streptococci, both as prophylactic and therapeutic measures. As a rule, the experimental work has been carried out on rabbits, an animal known to be susceptible to this organism. Weaver ${ }^{17}$ concluded that killed streptococci, injected into an animal, may raise its resistance to the living strain. Simonds, ${ }^{19}$ as well as Tunnicliff ${ }^{19}$ have called attention to the effect of streptococci on the streptococco-opsonic index in scarlet fever-causing a positive phase after a primary negative phase. Moore ${ }^{20}$ noted that the injection of a streptococcic vaccine protected many rabbits from arthritis when hemolytic strains of streptococci were used, the immunity lasting 40 days. Clinically, the use of streptococcic vaccines can be summed up by the statement of Gay, ${ }^{21}$ who, in a comprehensive review of the streptococcus problem, says that "streptococcus vaccines have not been used to any considerable extent as a means of protection against streptococcus infection."

The early observers in the field of vaccinotherapy were insistent that raccine be autogenous when employed as a curative agent. This,

\footnotetext{
15 Lancet, 1902, 1, p. 651; 1907, 2, p. 493.

${ }_{18}$ Centralbl. f. Bakteriol., 1892, 12, p. 192.

17 Tr. Assn. Am. Phys., 1910, 8, p. 223.

18 Jour. Infect. Dis., 1907, 4, p. 595.

19 Jour. Infect. Dis., 1907, 4, p. 304.

20 Jour. Infect. Dis., 1914, 15, p. 215.

21 Jour. Lab. and Clin. Med., 1918, 3, p. 722.
} 
of course, is impossible when the vaccine is used as a prophylactic, but Rosenow $^{22}$ advocates utilization of organisms found in the upper respiratory passages of persons in a given community during a given outbreak. Mellon ${ }^{23}$ thought that the best results were obtained from the use of streptococci of proved immunizing power.

The organisms employed in this vaccine were killed by heating to $56 \mathrm{C}$. for 1 hour and then mixing with $0.5 \%$ phenolized salt solution. As Wayson ${ }^{24}$ indicates, the guiding principle for vaccines has been conservation of all the "immunogenic qualities" and the destruction of infectivity of the principles of the vaccine. There is some reason to believe that these "immunogenic qualities" are partially impaired by heating to $56 \mathrm{C}$. for an hour, as Weaver ${ }^{17}$ reports better results with streptococci killed in strong galactose solutions at $35 \mathrm{C}$. and states that heating interferes with the antigenic properties of streptococci. However, the heat killed method, plus a weak solution of phenol or tricresol, has proven efficient in the hands of numerous investigators and is the procedure generally chosen.

The advocates of vaccinotherapy usually recommend beginning with small doses rather than large ones. Wright, himself, laid stress on the fact that the dosage should be sufficiently small to excite only a mild, local and constitutional reaction. Adami, ${ }^{25}$ in discussing the basic factors governing the use of vaccines, emphasized this point. Simonds ${ }^{18}$ showed, in his experimental work on rabbits, that relatively small doses of streptococci may cause a greater rise in the opsonic index than large doses. On the other hand, Cecil and Austin, ${ }^{26}$ in their work at Camp Upton, with pneumococcal vaccine, observed that the degree of response to the vaccination appeared to be dependent on the total dosage of each type of pneumococci administered. Boughton $^{27}$ reports good results by using an initial dose of 100 million homologous, galactose-killed streptococci in local streptococcic complications of scarlatina and erysipelas. Stitt ${ }^{28}$ quotes Wilson as recommending from 6-68 million as the minimum and maximum doses for streptococcic vaccines. Kolmer ${ }^{29}$ gives from 25-200 million per mil,

22 Jour. Am. Med. Assn., 1919, 72, n. 31.

${ }^{2 x}$ Med. Record, 1915, 87, p. 809.

24 Jour. Am. Med. Assn., 1917, 67, p. 267.

25 Tr. Assn. Am. Phys., 1910, p. 211.

28 Jour, Exper. Med., 1918, 28, p. 14

27 Jour. Infect. Dis., 1910, 7, p. 99.

2s Practical Bacteriology, Blood Work, Parasitology, 1918, p. 214.

20 Infection. Immunity and Specific Therapy, 1917, p. 223. 
as the usual limits of dosage for a streptococcic vaccine. Thomas and $\mathrm{Ivy}^{30}$ advocate from 2-200 million, with an average dose of 25-50 million, while Park and Williams ${ }^{31}$ vary the dose from 5-10 to 100 million or higher. Ely, Lloyd, Hitchcock and Nickson ${ }^{32}$ report beneficial results with respect to the prophylaxis of influenza in a large group of men when $0.25,0.5$ and 1 mil of a streptococcic vaccine, containing 250 million of these organisms-per mil-were given.

When it is remembered that the vaccine used on the volunteers contained approximately 100 million per mil and that a total of about 230 million were given, it would appear that the amount was well within logical limits, particularly in the light of the relatively mild focal or constitutional reactions among those who received it.

From what has been said, it is reasonable to suppose that in the choice of organisms, the mode of preparation, the dosage and the manner of administration, there was nothing of a technical nature which would preclude the vaccine from being efficacious.

\section{SUM MARY}

During the recent investigations of 155 human volunteers to study the epidemiology of influenza, 16 different individuals developed tonsillitis apparently due to hemolytic streptococci.

All cases of tonsillitis occurred in men receiving crude nasopharyngeal washings and bronchial secretions from early, acute, typical, uncomplicated influenza patients-with exception of six cases in which the common donor had acute tonsillitis; no cases of tonsillitis occurred in those into whose nares were instilled filtered nasopharyngeal washings and bronchial secretions from influenza donors.

The catisative organisms of the tonsillitis were very similar to the hemolytic streptococci isolated from the nasopharyngeal washings and bronchial secretions of the donors of the respective groups.

Three of the cases of tonsillitis developed in persons who had received, one month previously, a vaccine containing, in addition to other organisms, three presumably adequate doses of hemolytic streptococci.

ao Applied Immunology, 1915, p. 251.

91 Pathogenic Micro-organisms, 1917, p. 590.

32 Jour. Am. Med. Assn., 1919, 72, p. 24. 